\title{
Value of positive myocardial infarction imaging in coronary care units
}

\author{
S P JOSEPH, A V PEREIRA-PRESTES, P J ELL, R DONALDSON, \\ W SOMERVILLE, R W EMANUEL
}

British Medical fournal, 1979, 1, 372-374

\section{Summary and conclusions}

Positive myocardial imaging was undertaken on 120 unselected patients admitted to a coronary care unit with clinical suspicion of acute myocardial infarction. Multipurpose mobile gamma-cameras were used for serial imaging after administration of $99 \mathrm{~m}$ technetiumlabelled imidodiphosphonate, a low-cost radiopharmaceutical that is $97 \%$ specific for myocardial necrosis, with myocardial uptake and blood clearance most suitable for myocardial imaging. The sensitivity of detection was $94 \%$ for patients whose infarction was unequivocal on the ECG; when the presence of raised enzyme concentrations was also used as a criterion for myocardial necrosis, the overall sensitivity for all 120 patients remained $94 \%$. In 73 patients $(61 \%)$, whose ECGs were unhelpful or difficult to interpret, scintigraphy allowed infarction to be diagnosed in $11(15 \%)$ and to be excluded in five (7\%). In $32(44 \%)$ of this group whose ECGs were totally uninterpretable due to previous myocardial damage or disorders of electrical activation, scintigraphy provided confirmation of a diagnosis that otherwise rested only on whether enzyme concentrations were raised.

Myocardial imaging is thus a useful technique that permits more definite diagnosis in patients for whom ECG and enzyme data are uncertain.

\section{Introduction}

Radioisotope imaging of acute myocardial infarction ${ }^{1}$ may be achieved by using either radiopharmaceuticals which perfuse normal myocardium and show infarction as a negative shadow (negative imaging) ${ }^{2} 3$ or agents that are selectively concentrated in necrotic areas (positive imaging).$^{3-6}$ Although negative imaging yields results during the first few hours after infarction, it is less satisfactory since it cannot differentiate between old and new myocardial damage, cannot be used for serial imaging or sizing of infarction against time or treatment, is highly expensive, and has inappropriate energy levels and myocardial uptake for optimal gamma-camera imaging. The low cost of radiopharmaceuticals for positive imaging (usually ${ }^{9} \mathrm{~m}_{\text {technetium-labelled phosphates) justifies their continued }}$ use as a routine aid to diagnosis in suspected acute myocardial infarction.

Most reports have described the use of ${ }^{9} \mathrm{~m}_{\text {technetium- }}$ labelled pyrophosphate ( $\left.{ }^{99 \mathrm{~m} T c-P y P}\right)$, and, although this

\footnotetext{
Departments of Nuclear Medicine and Cardiology, The Middlesex Hospital and Medical School, London W1N 8AA

$S$ P JOSEPH, MA, MRCP, senior registrar in cardiology A V PEREIRA-PRESTES, fellow in nuclear cardiology P J ELL, MD, MSC, consultant in nuclear medicine $R$ DONALDSON, MD, MRCP, senior registrar in cardiology W SOMERVILLE, MD, FRCP, consultant cardiologist R W EMANUEL, DM, FRCP, consultant cardiologist
}

technique achieves satisfactory imaging, it has not gained widespread acceptance. It has a relatively low specificity, giving many false-positive results, ${ }^{7-10}$ and a fairly high incidence of false-negative scans - that is, a doubtful sensitivity-which has tended to limit its application. ${ }^{11}$ To estimate sensitivity and specificity, however, imaging results must be compared with ECG and enzyme evidence. ${ }^{7} \times$ As these latter techniques are themselves less than $100 \%$ sensitive and specific, their value as a standard by which to judge a new technique is unsatisfactory and may give an inaccurate assessment. Any assessment of myocardial infarction imaging should therefore take account of the limits of conventional enyzme and ECG methods.

Radioisotope imaging, if of sufficient sensitivity and specificity, would be of value in diagnosing myocardial infarction, as uninterpretable or unhelpful ECGs are common and enzyme data may yield borderline or, later in the evolution of the infarction, normal results. Animal and clinical data have shown that $99 \mathrm{~m}$ technetium-labelled imidodiphosphonate ( ${ }^{9} \mathrm{~m}$ Tc-IDP) has a considerably higher specificity for necrotic myocardium and is more rapidly cleared from blood than ${ }^{99 m}$ Tc-PyP. ${ }^{12}{ }^{13} \mathrm{We}$ therefore carried out a study to establish whether information derived from acute positive myocardial infarction imaging with ${ }^{99 \mathrm{~m}} \mathrm{Tc}-\mathrm{IDP}$ was sufficiently reliable and added sufficient useful additional information to other routine diagnostic tools to justify its routine use in patients admitted to acute coronary care units.

\section{Patients and methods}

One hundred and twenty consecutive and unselected patients who were admitted to the coronary care unit entered the study. All were suspected of having, and were treated for, acute myocardial infarction on clinical criteria. Eighty-two patients gave histories of typical cardiac pain unrelieved by rest or nitrates for 15 minutes or longer; 29 of chest pain that was atypical in type or site; and four of unexplained syncope. Five patients were free of chest pain but developed unexplained left ventricular failure. These last nine patients were suspected of having silent infarction. Patients with evidence of acute benign pericarditis or pre-existing left ventricular aneurysms were excluded from the study. The patients were imaged using a high-resolution small-field mobile gamma-camera (Searle Low Energy Mobile and Ohio Nuclear Sigma-420 gamma-cameras) brought to their bedside one hour after intravenous administration of $10 \mathrm{mCi}$ of ${ }^{99 \mathrm{~m}} \mathrm{Tc}$-IDP as described. ${ }^{12}$

A total of 400000 counts were collected in each of the anteroposterior, left anterior oblique, and left lateral views. Imaging began on the day of admission and was repeated once daily. Any negative scans were repeated, and positive scans were repeated in all cases for four days after admission. Two independent observers with no clinical information assessed the scans and graded them $1+$ to $4+$ according to Parkey's criteria. ${ }^{4}$ Scans rated $2+, 3+$, and $4+$ in any of the three views were considered to be positive for ${ }^{99} \mathrm{~m}^{\prime} \mathrm{Tc}-\mathrm{IDP}$ uptake.

Routine daily 12-lead ECGs were recorded and serial estimations of serum creatine phosphokinase (CK) concentrations made; two samples were taken for CK estimation in the first 18 hours and thereafter at daily intervals. In men serum $\mathrm{CK}$ concentrations above $150 \mathrm{IU} / 1$ were considered to be raised, 100-150 IU/l borderline, and below $100 \mathrm{IU} / 1$ normal; in women concentrations above $130 \mathrm{IU} / 1$ were regarded as raised, 80-130 IU/l borderline, and below $80 \mathrm{IU} / 1$ normal. ECGs were analysed for evidence of full-thickness myocardial infarction, ${ }^{14}$ and a subendocardial infarction was diagnosed according 
to the criteria of Friedberg ${ }^{15}$ and also, for this study, in the presence of T-wave inversion without ST-segment changes. ECGs were also analysed for pre-existing myocardial damage, including previous myocardial infarction; ventricular hypertrophy; and disorders of electrical activation, which included bundle-branch block, preexcitation, and ventricular pacing.

\section{Results}

Transmural infarction-Forty-seven patients had ECG evidence of transmural infarction, and of these, 44 had positive ${ }^{99 \mathrm{~m}} \mathrm{Tc}$-IDP scans. All had raised serum $\mathrm{CK}$ concentrations. Three patients with negative scans had inferior myocardial infarctions.

Subendocardial infarction-Twenty patients were judged to have subendocardial infarction on the basis of ECG criteria. Fourteen had positive and six negative scans. Thus, on the basis of ECG criteria alone, the sensitivity of detection was $70^{\circ}{ }_{i o}$. The table gives the results of the ECGs and scans according to the serum CK concentrations. Three patients with negative scans had borderline enzyme concentrations. Thus 17 patients had a positive scan and abnormal ECG, a positive scan and raised enzyme concentrations, or an abnormal ECG and raised enzyme concentrations-that is, two abnormalities out of three. If these patients are considered to have had true myocardial infarction, the sensitivity of detection by $99 \mathrm{~m}$ Tc-IDP scanning is 14 out of $17\left(82^{\circ}, 0\right)$. Seven patients with normal or borderline enzyme concentrations had positive scans.

Results of ECG and scan using $99 \mathrm{~m}$ technetium-labelled imidodiphosphonate $\left({ }^{99} \mathrm{~m} T c-I D P\right)$ and serum creatine kinase concentrations in 120 patients with suspected myocardial infarction. ECGs showing other than transmural infarction were considered to be non-diagnostic

\begin{tabular}{|c|c|c|c|c|c|}
\hline \multirow{2}{*}{ ECG } & \multirow{2}{*}{$\begin{array}{c}\text { No of } \\
\text { patients }\end{array}$} & \multirow{2}{*}{$\begin{array}{l}{ }^{98} \mathrm{~m} \text { Tc- } \\
\text { IDP Scan }\end{array}$} & \multicolumn{3}{|c|}{ Serum CK concentration } \\
\hline & & & Raised & Borderline & Normal \\
\hline Transmural infarction & $\begin{array}{r}44 \\
3\end{array}$ & $\begin{array}{c}\text { Positive } \\
\text { Negative }\end{array}$ & $\begin{array}{r}44 \\
3\end{array}$ & & \\
\hline $\begin{array}{l}\text { Subendocardial } \\
\text { infarction }\end{array}$ & $\begin{array}{r}14 \\
6\end{array}$ & $\begin{array}{l}\text { Positive } \\
\text { Negative }\end{array}$ & $\begin{array}{l}7 \\
3\end{array}$ & 1 & 6 \\
\hline Abnormal & $\begin{array}{l}13 \\
23\end{array}$ & $\begin{array}{l}\text { Positive } \\
\text { Negative }\end{array}$ & 9 & 3 & $\begin{array}{r}1 \\
23\end{array}$ \\
\hline Normal & 17 & $\begin{array}{l}\text { Positive } \\
\text { Negative }\end{array}$ & 1 & 2 & 14 \\
\hline
\end{tabular}

Abnormal ECGs-Of 36 patients in this group, 13 had positive and 23 negative scans. None with negative scans had raised enzyme concentrations. Four patients with normal or borderline enzyme concentrations had positive scans.

Normal ECGs-The 17 patients in this group all had negative scans, and only one had appreciably raised serum $\mathrm{CK}$ concentrations.

\section{Discussion}

Physicians in charge of coronary care units encounter diagnostic problems when enzyme evidence conflicts with ECG data, the ECGs are totally unhelpful, or enzyme concentrations are only slightly raised. Thus a third diagnostic tool of greater specificity and sensitivity than other imaging agents is of great help.

Our results may be appraised only by knowing the underlying sensitivity and specificity of the method used to diagnose acute myocardial infarction. The specificity indicates the number of false-positive results. Experimental evidence has suggested that imaging with ${ }^{99 \mathrm{~m}} \mathrm{Tc}-\mathrm{PyP}$ is highly specific for irreversibly damaged myocardium. ${ }^{16} 17$ In two clinical studies, however, the number of false-positive results was $14 \% \%$ and $20 \%{ }^{9} 10$ These figures would render the technique of limited value for detecting acute myocardial infarctions when other criteria are equivocal. False-positive results are mainly due to blood-pool imaging of the heart chambers, ${ }^{1018}$ a consequence of the delayed clearance of ${ }^{99 \mathrm{~m}} \mathrm{Tc}-\mathrm{PyP}$. Other causes are calcified left ventricular aneurysms and previous recent myocardial infarction. ${ }^{78}$
In a previous study at this centre ${ }^{12}$ the specificity of imaging with ${ }^{9}$ 9m Tc-IDP was $97^{\circ} \%$ in a group of patients with no evidence of cardiac disease, who were undergoing bone scanning to detect skeletal malignant deposits; only one patient out of 30 had a positive scan, thought to represent a false-positive result. The

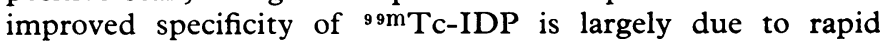
clearance, which prevents blood-pool imaging and renders false-positive results from this cause unlikely, ${ }^{12}$ together with a fivefold increase in uptake in necrosed heart when compared with other ${ }^{99 \mathrm{~m}}$ Tc-labelled phosphates. ${ }^{13}$

Minor degrees of infarction in the absence of ECG changes are well known. ${ }^{99 \mathrm{~m}}$ Tc-PyP imaging seems to be a more sensitive indicator of minor degrees of myocardial necrosis than either ECGs or serum enzyme concentrations. ${ }^{19-21}$ It has been impossible, however, to distinguish false- from true-positive scans because of the apparent low specificity of $99 \mathrm{~m}$ Tc-PyP. A major contribution of ${ }^{99 \mathrm{~m}}$ Tc-IDP seems to be its ability to reduce the number of false-positive scintigrams and permit the diagnosis of subendocardial infarction in the absence of clearcut ECG or enzyme evidence.

Judging the sensitivity, an index of the proportion of disease detected-that is, the number of false-negative results-is more difficult. It requires certain knowledge of whether infarction has actually been sustained, and ECG or enzyme data are not always sufficiently reliable. ${ }^{22}$ In this series the sensitivity of detection of myocardial infarction when the ECG evidence was unequivocal was $94 \%$. Although it may not be strictly accurate to apply this figure when the ECG is less clear, there was an extremely close correlation between negative scans and normal or borderline enzyme concentrations in 53 patients with ECGs that were unhelpful (normal or uninterpretable). The figure of $70 \%$ for the sensitivity of detection of subendocardial infarction, judged on ECG data alone, may therefore be misleading and low because the ECG changes are not sufficiently reliable. If the three patients with such ECG changes but borderline enzyme concentrations are considered to be negative for infarction the sensitivity of detection rises to $82 \%$. Only seven out of all 120 patients had either definitely raised serum enzyme concentrations or unequivocally diagnostic ECGs together with negative scans-that is, only seven undoubted false-negative results occurred-and the sensitivity of detection for all patients is then $94 \%$. Therefore, a totally normal scan suggests that there is less than a $6 \%$ chance that the patient has infarction and that some other cause of pain should be sought. In the 73 patients (61\% of the whole group) with unhelpful ECGs there were five $(7 \%)$ patients with borderline serum CK concentrations in whom a negative scan permitted a more certain elimination of myocardial infarction.

There were thus 16 patients ( 11 with positive scans, five with negative scans) in whom the scan was diagnostic when the ECGs and CK concentrations were misleading. This represents $13 \%$ of all 120 patients $(22 \%$ of the 73 patients with unhelpful ECGs). To appreciate the full worth of ${ }^{99 \mathrm{~m} T c-I D P}$ scanning, it is important also to remember the additional 32 patients with totally uninterpretable ECGs, in whom scintigraphy provided a useful addition to enzyme data in confirming the diagnosis. These patients represent $27 \%$ of the whole group of 120 (44\% of those with unhelpful ECGs).

By estimating CK MB isoenzyme concentrations as well as using positive myocardial scanning the specificity of the diagnosis will be further improved. ${ }^{23}$ These two diagnostic methods are, however, complementary rather than exclusive: the CK MB concentration becomes normal after the first 24 hours, when the scan becomes abnormal. The scan is therefore a more useful investigation for the patients who present late.

Most regions in the UK now have facilities for isotope imaging; with the low cost of the radiopharmaceutical and the reduced cost of the new generation of mobile gamma-cameras regional or area mobile scanning can provide bedside nuclear medicine diagnostic techniques. Incorporating into the facilities of nuclear medicine departments a myocardial imaging service for coronary care units will permit more certain diagnosis in 
an important minority of patients in whom existing techniques frequently do not provide a clear diagnosis.

AVP is supported by the Conselho Nacional de Desenvolvimento Cientifico e Tecnologico, Brazil.

Requests for reprints should be addressed to Dr P J Ell, Department of Nuclear Medicine, The Middlesex Hospital Medical School, London W1N 8AA.

\section{References}

1 Carr, E A, et al, American Heart fournal, 1962, 64, 650.

2 Wackers, F J Th, et al, European fournal of Cardiology, 1976, 4, 273.

${ }^{3}$ British Medical fournal, 1978, 2, 717.

4 Parkey, R W, et al, Seminars in Nuclear Medicine, 1977, 7, 15.

5 Ennis, J T, Walsh, M J, and Mahon, J M, British Medical fournal, 1975, 3, 517 .
6 Lancet, 1978, 2, 299

7 Ahmad, M, et al, American fournal of Cardiology, 1977, 39, 50.

${ }^{8}$ Cowley, M K, et al, Circulation, 1977, 56, 192.

9 Berman, D S, et al, Circulation, 1975, 51, suppl No 2, p 53.

10 Prasquier, R, et al, Circulation, 1977, 55, 61.

11 Ahmad, M, Berman, D S, and Masion, D T, Americanfournal of Cardiology, 1978, 41, 349.

12 Joseph, S P, et al, British Heart fournal, 1978, 40, 234.

13 Ell, P J, et al, British Heart fournal, 1978, 40, 226.

14 McConahay, D R, et al, Circulation, 1970, 42, 245.

${ }^{15}$ Friedberg, C K, Diseases of the Heart, p 822. London, Saunders, 1966.

${ }^{16}$ Klein, M S, et al, Circulation, 1975, 51, suppl No 2, p 52.

17 Schelbert, H, et al, Circulation, 1975, 51, suppl No 2, p 70.

18 Klein, M S, American fournal of Cardiology, 1977, 39, 360.

19 Donsky, M S, British Heart fournal, 1976, 38, 257.

20 Willerson, J T, Circulation, 1976, 53, suppl No 1, p 128.

${ }^{21}$ Stern, S, et al, European fournal of Cardiology, 1977, 6, 167.

${ }^{22}$ Sobel, B E, and Shell, W E, Circulation, 1972, 45, 471.

${ }^{23}$ Coleman, R E, American fournal of Cardiology, 1976, 37, 732.

\title{
Successful treatment of exophthalmos and pretibial myxoedema with plasmapheresis
}

\author{
P DANDONA, N J MARSHALL, S P BIDEY, A NATHAN, C W H HAVARD
}

British Medical fournal, 1979, 1, 374-376

\section{Summary and conclusions}

A patient with Graves's disease with acute progressive exophthalmos and pretibial myxoedema was treated twice with plasmapheresis. Two weeks after the first treatment the symptoms recurred, but 20 weeks after the second treatment the exophthalmos was much improved and the pretibial myxoedema had disappeared. Analysis of sequential serum IgG concentrations and the thyroid-stimulating immunoglobulin index suggested that the two conditions were caused by specific IgGs.

The results suggest that plasmapheresis has a useful place in the treatment of acute and rapidly progressive ophthalmopathy and pretibial myxoedema in patients with Graves's disease.

\section{Introduction}

Graves's disease is characterised by abnormal immunoglobulin G's (IgG) in the plasma. Some of these displace thyrotrophin (TSH) bound to the thyroid follicular cell membran $\mathrm{e}^{1-5}$ and are known as thyroid-stimulating immunoglobulins (TSI). Others have biological effects on orbital tissues, ${ }^{6-11}$ are specific to sera from patients with exophthalmos, and may have a role in the pathogenesis of the ophthalmic complications of Graves's disease.

\section{Royal Free Hospital, London NW3 2QG}

P DANDONA, MRCP, DPHIL, director of metabolic unit

A NATHAN, MRCP, registrar, departments of chemical pathology and endocrinology

C W H HAVARD, DM, FRCP, consultant physician and endocrinologist

Middlesex Hospital and Medical School, London W1

N J MARSHALL, PHD, lecturer

S P BIDEY, PHD, research fellow, department of nuclear medicine
Plasmapheresis is an effective treatment in Goodpasture's syndrome $\mathrm{e}^{12}$ and myasthenia gravis, ${ }^{13}{ }^{14}$ where specific circulating IgGs mediate the basic injury. Hence it seemed appropriate to use plasma exchange in a patient with Graves's disease with progressive exophthalmos and pretibial myxoedema. We report the response of this patient in terms of both the clinical remission observed and sequential changes in serum IgG concentrations and TSI index.

\section{Case report}

A 57-year-old Caucasian woman presented in August 1977 with abdominal pain, diarrhoea, anxiety, palpitation, dyspnoea, and ankle swelling. She had pronounced tremor, proximal myopathy, and a diffuse, firm enlargement of the thyroid with a bruit. There was lid-lag but no lid retraction and no exophthalmos. Four years before she had had a left-sided radical mastectomy for carcinoma. Three female cousins of her father had had thyroid disease, and her husband had had recurrent thyrotoxicosis. Both her serum thyroxine (T4) concentration and free thyroxine index (FTI) were raised (T4 $199 \mathrm{nmol} / \mathrm{l}(15.5 \mathrm{\mu g} / 100 \mathrm{ml})$; FTI $\left.297^{\circ}{ }^{\circ}\right)$. She was given $30 \mathrm{mg}$ carbimazole daily, propranolol, and cyclopenthiazide-K but within three weeks developed an irritating exanthematous rash. The drugs were stopped, and in September she was treated with iodine - 131 $(10 \mathrm{mCi})$. Metoprolol and cyclopenthiazide-K were added.

In November periorbital oedema with minimal exophthalmos were noted. In December there was limitation of the upward movement of both eyes and pretibial myxoedema had developed. Serum T4 was still raised. Propylthiouracil $300 \mathrm{mg}$ daily was started. By January 1978 the pretibial myxoedema was more pronounced, and local Dermojet injections of triamcinolone (total dose $35 \mathrm{mg}$ ) into the lesions were administered. No noticeable improvement occurred. By March the pretibial myxoedema lesions had become hairy, pruritic, and greatly indurated. Onycholysis had appeared. Exophthalmos was severe (exophthalmometry: right $24 \mathrm{~mm}$, left $24 \mathrm{~mm}$ ). There was no upward movement of the eyes, and pronounced injection and chemosis of both conjunctivae were present. She was clinically and biochemically hypothyroid. Thyroxine $(0 \cdot 1 \mathrm{mg}$ daily) was added to the propylthiouracil treatment.

In view of the relentless progress of the exophthalmos and the risk of corneal injury she was admitted to hospital for plasmapheresis. She was given four sessions of plasma exchange on four successive days (plasmapheresis 1), carried out through a catheter in the femoral vein 